\title{
Synthesis and Characterization of Polyimides from Unsymmetrical Diamine with Cyano Groups
}

\author{
Hyun A KANG, Im Sik ChUNG, Masa-aki KaKIMOTo, ${ }^{*}$ and Sang Youl $\mathrm{KIM}^{\dagger}$ \\ Center for Advanced Functional Polymers, Department of Chemistry and School of Molecular Science \\ (BK 21), Korea Advanced Institute of Science and Technology, 373-1 Kusung-Dong, Yusung-Gu, Taejon 305-701, Korea \\ * Department of Organic and Polymeric Materials, Tokyo Institute of Technology, Meguro-ku, Tokyo 152-8552, Japan
}

(Received October 31, 2000; Accepted December 14, 2000)

\begin{abstract}
A new diamine monomer containing cyano group, 2-cyano-4,4'-diaminodiphenyl ether, was synthesized and polymerized to polyimides with several aromatic dianhydrides via two kinds of imidization methods, namely, thermal or solution imidization methods. By the thermal imidization method, tough, flexible, and creasable polyimide films were obtained except the polyimide from pyromellitic dianhydride. The polyimides have high $T_{\mathrm{g}}$ values and are stable up to $500^{\circ} \mathrm{C}$ in air. The polyimide made from the diamine and $4,4^{\prime}$-oxyphthalic anhydride via solution imidization method was partially soluble in polar aprotic solvents, but it becomes soluble when the cyano groups are hydrolyzed.

KEY WORDS Polyimide / Unsymmetrical Diamine / 2-Cyano-4,4'-diaminodiphenyl Ether / Solution Imidization /
\end{abstract}

Recent technological advances in space and other areas have generated a continuing and growing need for materials that withstand prolonged exposures at temperature in excess of $300^{\circ} \mathrm{C}$ and/or relatively short exposures at much higher temperature. The need has become particularly acute for high temperature materials used in electrical and thermal insulation, gaskets, flexible tubing, advanced composites and many other items. Among high temperature polymers, aromatic polyimides were developed in the early 1960s and since then have been of great technological importance due to their high temperature stability, ${ }^{1,2}$ favorable dielectric properties and chemical resistance. And now aromatic polyimides find many applications in the composites and microelectronics.

However, most of polyimides encounter processing difficulties due to their infusibility and poor solubility in organic solvents that mainly come from strong interchain forces and chain rigidity. A great deal of research effort on the polyimides has been concerned on improvement of processability and other properties with minimal effect on thermal stability. ${ }^{3}$ For example, polyimides containing trifluoromethyl groups showed high modulus, low thermal expansion coefficient, and good solubility, ${ }^{4-7}$ and incorporation of heterocyclic units into polyimide chains increased the glass transition temperature and thermooxidative stability. ${ }^{8-11}$

Recently, we succeeded in synthesis of new soluble polyimides from the unsymmetrical diamine containing trifluoromethyl groups at 2-position of 4,4'diaminodiphenyl ether. ${ }^{12}$ These polyimides have improved solubility and their thermal properties are comparable to those of the polyimides without trifluoromethyl groups. Therefore, it is interesting to attach a cyano group, which is smaller than trifluoromethyl group but has stronger electron withdrawing characteristics, to the rigid aromatic polyimides not only because the cyano group may interfere chain in- teractions of the rigid polyimides but also because it can be transformed into other functional group. In this study, new diamine monomer containing cyano group, 2cyano-4,4'-diaminodiphenyl ether (2) was synthesized and polymerized with several dianhydrides, and the effect of the pendent cyano groups on the rigid aromatic polyimides was investigated.

\section{EXPERIMENTAL}

\section{Materials}

Pyromellitic dianhydride (PMDA) (Aldrich), 3,3',4,4'biphenyl tetracarboxylic dianhydride (BPDA) (Chriskev), 3,3',4,4'-benzophenone tetra-carboxylic dianhydride (BTDA) (Aldrich), and 4,4'-oxyphthalic anhydride (ODPA) (Oxychem) were recrystallized from acetic anhydride and then dried in vacuo at $150^{\circ} \mathrm{C}$ for $24 \mathrm{~h} .2$ Chloro-5-nitrobenzonitrile (Aldrich, 99\%), 4-nitrophenol (Acros, 98\%), and other commercially available reagent grade chemicals obtained from Aldrich and Junsei chemical company were used without further purification.

\section{Measurements}

${ }^{1} \mathrm{H}$ NMR and ${ }^{13} \mathrm{C}$ NMR spectra of synthesized compounds were recorded on Bruker AC $200(200 \mathrm{MHz}$ for ${ }^{1} \mathrm{H}$ and $50.3 \mathrm{MHz}$ for $\left.{ }^{13} \mathrm{C}\right)$ or AM $300\left(300 \mathrm{MHz}\right.$ for ${ }^{1} \mathrm{H}$ and $75.1 \mathrm{MHz}$ for ${ }^{13} \mathrm{C}$ ). FT-IR spectra of the monomer and the polymers were obtained with Bomem Michelson series FT-IR spectrophotometer using $\mathrm{KBr}$ pellet or film. High-resolution mass spectra (HRMS) of the synthesized compounds were obtained with a JEOL JMS-SX-102 mass spectrometer. Inherent viscosity of polymers was determined at $0.5 \mathrm{~g} \mathrm{dL}^{-1}$ at $30^{\circ} \mathrm{C}$. Differential Scanning Calorimetry (DSC), Thermogravimetric analysis (TGA) and Thermomechanical analysis (TMA) were performed on a TA 2200 thermal analyzer system. Melting points (mp) of the synthesized compounds and $T_{\mathrm{g}}$ 's of the poly-

\footnotetext{
† To whom all correspondence should be addressed (E-mail: kimsy@mail.kaist.ac.kr).
} 
mers were obtained with DSC instrument at a heating rate of $10^{\circ} \mathrm{C} \min ^{-1}$ in $\mathrm{N}_{2}$. TGA measurements were made at a heating rate of $10^{\circ} \mathrm{C} \mathrm{min}^{-1}$ in $\mathrm{N}_{2}$ and air, respectively. The coefficients of thermal expansion (CTEs) at the temperature range from $50^{\circ} \mathrm{C}$ to $250^{\circ} \mathrm{C}$ were obtained by using TMA at a heating rate of $5^{\circ} \mathrm{C} \min ^{-1}$ in $\mathrm{N}_{2}$.

2-Cyano-4,4'-dinitrodiphenyl Ether (1). A $250 \mathrm{~mL}$ three-necked round bottom flask containing DMF (60 $\mathrm{mL}$ ), 2-chloro-5-nitrobenzonitrile (7.03 g, $38.5 \mathrm{mmol})$, 4nitrophenol $(5.48 \mathrm{~g}, 39.4 \mathrm{mmol})$, and potassium carbonate $(15.0 \mathrm{~g}, 109 \mathrm{mmol})$ was fitted with a reflux condenser, a nitrogen inlet and outlet. The reaction mixture was heated to $110^{\circ} \mathrm{C}$ and the temperature was maintained for 15 min under nitrogen. After it was cooled to ambient temperature, the reaction mixture was precipitated into water. The precipitated pink solid was filtered and dried in vacuo at $70^{\circ} \mathrm{C}$ for $12 \mathrm{~h}$. The yield of product was $10.8 \mathrm{~g}(98.2 \%)$. Mp: $150-152^{\circ} \mathrm{C}$. FT-IR $\left(\mathrm{KBr}, \mathrm{cm}^{-1}\right)$ : $2239(\mathrm{C} \equiv \mathrm{N}), 1616,1579$ (aromatic), 1524, $1482\left(\mathrm{NO}_{2}\right)$, $1253\left(\mathrm{C}-\mathrm{O}-\mathrm{C}\right.$ ). ${ }^{1} \mathrm{H}$ NMR (DMSO- $d_{6}, \mathrm{ppm}$ ): $7.29-7.33$ (d, $1 \mathrm{H}), 7.52-7.60(\mathrm{~d}, 2 \mathrm{H}), 8.36-8.40(\mathrm{~d}, 2 \mathrm{H}), 8.48-8.52$ (dd, $1 \mathrm{H}), 8.92-8.94(\mathrm{~d}, 1 \mathrm{H}) .{ }^{13} \mathrm{C}$ NMR (DMSO- $d_{6}, \mathrm{ppm}$ ): 104.27, 113.70, 116.6, 120.9, 126.5, 130.4, 130.7, 143.1, 144.6, 158.9, 161.9. HRMS (m/e): calc. for $\mathrm{C}_{13} \mathrm{H}_{7} \mathrm{~N}_{3} \mathrm{O}_{5}$, 285.0386; found, 285.0380 .

2-Cyano-4,4'-diaminodiphenyl Ether (2). A mixture of $1(10.8 \mathrm{~g}, 37.8 \mathrm{mmol}), \mathrm{SnCl}_{2}(49.9 \mathrm{~g}, 263 \mathrm{mmol})$ and $95 \%$ ethanol $(120 \mathrm{~mL})$ was stirred while concentrated $\mathrm{HCl}(90 \mathrm{~mL})$ was added slowly. After addition of $\mathrm{HCl}$ was over, the mixture was refluxed for $13 \mathrm{~h}$. Excess ethanol was evaporated and the remaining solution was poured into water. The solution was basified with $20 \%$ $\mathrm{NaOH}$ solution and the precipitate was filtered and recrystallized from $\mathrm{CHCl}_{3}$ /hexane to give light brown product. The yield was $6.42 \mathrm{~g}(75.5 \%)$. Mp: $125-127^{\circ} \mathrm{C}$. FTIR $\left(\mathrm{KBr}, \mathrm{cm}^{-1}\right): 3417,3338,3221\left(\mathrm{NH}_{2}\right), 2227(\mathrm{C} \equiv \mathrm{N})$, $1262(\mathrm{C}-\mathrm{O}-\mathrm{C}) .{ }^{1} \mathrm{H}$ NMR (DMSO- $\left.d_{6}, \mathrm{ppm}\right): 4.93$ (s, 2H), $5.25(\mathrm{~s}, 2 \mathrm{H}), 6.52-6.58(\mathrm{dd}, 2 \mathrm{H}), 6.63-6.74(\mathrm{~m}, 3 \mathrm{H})$, $6.77-6.83$ (dd, $2 \mathrm{H}) .{ }^{13} \mathrm{C}$ NMR (DMSO- $\left.d_{6}, \mathrm{ppm}\right): 102.67$, $114.79,116.21,116.73,119.09,119.41,120.40,144.53$, 145.16, 146.80, 150.24. HRMS Polyimide (m/e): calc. for $\mathrm{C}_{13} \mathrm{H}_{11} \mathrm{~N}_{3} \mathrm{O}$, 225.0902; found, 285.0905.

Model Compound (3). A mixture of $2(0.308 \mathrm{~g}, 1.37$ mmol) and phthalic anhydride $(0.418 \mathrm{~g}, 2.62 \mathrm{mmol})$ in DMAc ( $7 \mathrm{~mL}$ ) was stirred under $\mathrm{N}_{2}$ at room temperature for $5 \mathrm{~h}$. To this solution, acetic anhydride $(0.45 \mathrm{~mL}, 4.44$ $\mathrm{mmol})$ and pyridine $(0.25 \mathrm{~mL}, 2.97 \mathrm{mmol})$ were added to form the imide ring. After addition of acetic anhydride and pyridine, the solution was stirred at room temperature for $12 \mathrm{~h}$. Within $1 \mathrm{~h}$, the precipitation was formed. The product was poured into water, filtered and washed with hot water and methanol, repeatedly. The product was dried in vacuo at $80^{\circ} \mathrm{C}$ for $12 \mathrm{~h}$. The yield of product was $0.61 \mathrm{~g}(91.9 \%)$. Mp: $270-271^{\circ} \mathrm{C}$. FT-IR $\left(\mathrm{KBr}, \mathrm{cm}^{-1}\right)$ : $2231(\mathrm{C} \equiv \mathrm{N}), 1780,1717(\mathrm{C}=\mathrm{O}$ stretching $), 1380(\mathrm{C}-\mathrm{N}$ stretching), 1260 (C-O-C), $719\left(\mathrm{C}=\mathrm{O}\right.$ bending). ${ }^{1} \mathrm{H}$ NMR (DMSO- $\left.d_{6}, \mathrm{ppm}\right): 7.21-7.26(\mathrm{~d}, 1 \mathrm{H}), 7.38-7.42(\mathrm{~d}, 2 \mathrm{H})$, $7.56-7.61(\mathrm{~d}, 2 \mathrm{H}), 7.79-7.84(\mathrm{dd}, 1 \mathrm{H}), 7.88-7.99(\mathrm{~m}, 8$ $\mathrm{H}), \quad 8.01-8.05$ (dd, $1 \mathrm{H}) .{ }^{13} \mathrm{C} \mathrm{NMR}$ (DMSO- $\left.d_{6}, \quad \mathrm{ppm}\right)$ : $103.18,115.13,118.31,119.96,123.43,123.57,127.41$, $128.80,129.43,131.44,131.53,132.64,134.48,134.70$, $134.86,154.10,157.78,166.63,166.94$. HRMS (m/e): calc. for $\mathrm{C}_{29} \mathrm{H}_{15} \mathrm{~N}_{3} \mathrm{O}_{5}$, 485.1012; found, 485.1013.

Polyimide. Polyimides were prepared either by the synthesis of poly(amic acid)s from diamine and dianhydride monomers with subsequent thermal cure to polyimides or by a one-pot solution imidization method at elevated temperature. Typical examples are given below.

Thermal Imidization. Polyimides (PIs) were prepared by a general procedure described below for PI1(4): PMDA $(0.688 \mathrm{~g}, 3.15 \mathrm{mmol})$ was added to the stirred solution of $2(0.710 \mathrm{~g}, 3.15 \mathrm{mmol})$ in DMAc $(14 \mathrm{~mL}$, solid content $10 \mathrm{w} / \mathrm{v} \%)$ and the reaction mixture was stirred for $12 \mathrm{~h}$ at ambient temperature under $\mathrm{N}_{2}$. The inherent viscosity of the poly(amic acid) was $0.47 \mathrm{dL} \mathrm{g}^{-1}$. The IR spectrum of poly(amic acid) exhibited absorptions at $3276 \mathrm{~cm}^{-1}(\mathrm{~N}-\mathrm{H} \mathrm{str})$ and $1715,1662 \mathrm{~cm}^{-1}(\mathrm{C}=\mathrm{O} \mathrm{str})$, i.e., corresponding to the poly(amic acid). The poly(amic acid) solution was then cast on a glass plate. The glass plate was preheated in vacuo at $70^{\circ} \mathrm{C}$ for $12 \mathrm{~h}$ to remove DMAc. Transparent and brown polyimide film was obtained by successive heating of the poly(amic acid) film from room temperature to about $300^{\circ} \mathrm{C}$ over $2 \mathrm{~h}$ and for 1 $\mathrm{h}$ at $300^{\circ} \mathrm{C}$ under a flow of argon. $T_{\mathrm{g}}: 428^{\circ} \mathrm{C}$. FT-IR (film, $\left.\mathrm{cm}^{-1}\right): 2234(\mathrm{C} \equiv \mathrm{N}), 1775,1727(\mathrm{C}=\mathrm{O}$ stretching $), 1378$ (C-N stretching), $739(\mathrm{C}=\mathrm{O}$ bending).

PI2(5) The inherent viscosity of the poly(amic acid) was $0.73 \mathrm{dL} \mathrm{g}^{-1}$. The IR spectrum of poly(amic acid) exhibited absorptions at $3265 \mathrm{~cm}^{-1}(\mathrm{~N}-\mathrm{H}$ str) and 1721 , $1655 \mathrm{~cm}^{-1}\left(\mathrm{C}=\mathrm{O}\right.$ str). $T_{\mathrm{g}}: 303^{\circ} \mathrm{C}$. FT-IR (film, $\left.\mathrm{cm}^{-1}\right)$ : $2234(\mathrm{C} \equiv \mathrm{N}), 1775,1716(\mathrm{C}=\mathrm{O}$ stretching $), 1376(\mathrm{C}-\mathrm{N}$ stretching), $739(\mathrm{C}=\mathrm{O}$ bending).

PI3(6) The inherent viscosity of the poly(amic acid) was $0.49 \mathrm{dL} \mathrm{g}^{-1}$. The IR spectrum of poly(amic acid) exhibited absorptions at $3267 \mathrm{~cm}^{-1}(\mathrm{~N}-\mathrm{H}$ str) and 1726 , $1671 \mathrm{~cm}^{-1}(\mathrm{C}=\mathrm{O} \mathrm{str}) . T_{\mathrm{g}}$ : $286^{\circ} \mathrm{C}$. FT-IR (film $\left.\mathrm{cm}^{-1}\right)$ : $2234(\mathrm{C} \equiv \mathrm{N}), 1779,1725(\mathrm{C}=\mathrm{O}$ stretching $), 1379(\mathrm{C}-\mathrm{N}$ stretching), 721 ( $\mathrm{C}=\mathrm{O}$ bending).

PI4(7) The inherent viscosity of the poly(amic acid) was $0.51 \mathrm{dL} \mathrm{g}^{-1}$. The IR spectrum of poly(amic acid) exhibited absorptions at $3265 \mathrm{~cm}^{-1}(\mathrm{~N}-\mathrm{H}$ str) and $1719,1664 \mathrm{~cm}^{-1}\left(\mathrm{C}=\mathrm{O}\right.$ str). $T_{\mathrm{g}}: 273^{\circ} \mathrm{C}$. FT-IR (film, $\left.\mathrm{cm}^{-1}\right): 2234(\mathrm{C} \equiv \mathrm{N}), 1779,1730(\mathrm{C}=\mathrm{O}$ stretching $), 1380$ (C-N stretching), 744(C=O bending).

One-pot Solution Imidization. Polyimides (PIs) were prepared by a general procedure described below for PI3 $^{\prime}\left(6^{\prime}\right)$ : A $100 \mathrm{~mL}$ round flask fitted with a nitrogen inlet and outlet and a mechanical stirrer was charged with $2(0.505 \mathrm{~g}, 2.24 \mathrm{mmol})$ and NMP ( $6 \mathrm{~mL}$, solid content 20 $\mathrm{w} / \mathrm{v} \%)$. After the diamine was completely dissolved in NMP, BTDA (0.722 g, $2.24 \mathrm{mmol})$ was added. The reaction was allowed to proceed overnight at room temperature under nitrogen. After $12 \mathrm{~h}$, the viscous poly(amic acid) solution was diluted to $10 \mathrm{w} / \mathrm{v} \%$ with additional NMP ( $6 \mathrm{~mL}$ ). The reaction flask was then fitted with a Dean-Stark trap and water condenser on the outlet side for thermal imidization. The reaction flask was heated to $180-190^{\circ} \mathrm{C}$ and the temperature was maintained for $9 \mathrm{~h}$ under a nitrogen purge. The water generated by imidization was distilled from the reaction mixture along with small amount of chlorobenzene. Within $3 \mathrm{~h}$, the brown gel was formed. The solution was then precipitated into water and methanol to isolate the polyimide as a solid. This solid was filtered and washed with 
hot water and methanol and dried in vacuo at $100^{\circ} \mathrm{C}$ overnight. The yield of product was $1.09 \mathrm{~g}(95.2 \%) . \eta_{\text {inh }}$ $=0.25 \mathrm{dL} \mathrm{g}^{-1} \cdot T_{\mathrm{g}}: 284^{\circ} \mathrm{C}$. FT-IR (film, $\left.\mathrm{cm}^{-1}\right): 2233(\mathrm{C} \equiv$ $\mathrm{N}), 1780,1726(\mathrm{C}=\mathrm{O}$ str $), 1377(\mathrm{C}-\mathrm{N}$ bending $), 720(\mathrm{C}=$ O bending).

PI4' $\mathbf{( 7}^{\prime}$ ) The polymerization proceeded homogeneously. The yield of product was $1.1 \mathrm{~g}(98.7 \%) . \eta_{\text {inh }}=0.59$ $\mathrm{dL} \mathrm{g}^{-1} . T_{\mathrm{g}}: 268^{\circ} \mathrm{C}$. FT-IR (film, $\left.\mathrm{cm}^{-1}\right): 2234(\mathrm{C} \equiv \mathrm{N}), 1780$, $1726(\mathrm{C}=\mathrm{O}$ stretching $), 1374(\mathrm{C}-\mathrm{N}$ stretching $), 743(\mathrm{C}=$ O bending).

\section{RESULTS AND DISCUSSION}

The new diamine monomer containing cyano group, 2cyano-4,4'-diaminodiphenyl ether (2) was prepared according to the reaction sequence of Scheme 1. 2-Cyano$4,4^{\prime}$-dinitrodiphenyl ether (1) was synthesized readily from 2-chloro-5-nitrobenzonitrile and 4-nitro-phenol in high yield $(98.2 \%)$. If the reaction time was longer than an hour, decomposition of the cyano group was observed. Dinitro compound 1 was reduced to the corresponding diamine monomer 2 which was recrystallized from $\mathrm{CHCl}_{3}$ /hexane. The structure of diamine monomer containing cyano group was confirmed by spectroscopic analyses.

Model reaction was conducted to investigate the reactivity of the diamine monomer and to obtain the model compound 3. The diamine monomer 2 was reacted with mono-functional phthalic anhydride. First, diamic acid was prepared, and then this intermediate was subsequently cyclodehydrated at room temperature with condensation reagents, acetic anhydride and pyridine, to give pale yellow diimide model compound 3 (Scheme 2). The structure of model compound was confirmed with IR and ${ }^{1} \mathrm{H}$ NMR spectra. FT-IR spectrum of 3 shows absorption bands at $2231 \mathrm{~cm}^{-1}$ corresponding to the $\mathrm{C} \equiv \mathrm{N}$ stretching, 1780 and $1717 \mathrm{~cm}^{-1}$ to $\mathrm{C}=\mathrm{O}$ imide asymmetric and symmetric stretching, $1380 \mathrm{~cm}^{-1}$ to $\mathrm{C}-\mathrm{N}$ imide stretching and $719 \mathrm{~cm}^{-1}$ to $\mathrm{C}=\mathrm{O}$ imide bending.

New polyimides containing cyano groups were prepared by using the conventional two-step procedure starting from 2-cyano-4,4'-diaminodiphenyl ether and commercially available aromatic dianhydrides, such as pyromellitic dianhydride (PMDA), 3,3',4,4'-biphenyl tetracarboxylic dianhydride (BPDA), 3,3', 4, $4^{\prime}$ benzophenone tetracarboxylic dianhydride (BTDA), and 4,4'-oxyphthalic anhydride (ODPA) through ringopening polyaddition and subsequent thermal cyclodehydration (Scheme 3).

The ring-opening polyaddition in DMAc at room temperature afforded poly(amic acid)s with inherent viscosity of $0.47-0.73 \mathrm{dL} \mathrm{g}^{-1}$. The thermal conversion to polyimides was carried out by successive heating of the poly(amic acid) films to $300^{\circ} \mathrm{C}$. For PI1(4), the final imidization temperature was $350^{\circ} \mathrm{C}$ instead of $300^{\circ} \mathrm{C}$ because of the high glass transition temperature $\left(T_{\mathrm{g}}\right)$ of PI1(4). The casting film of polyimide derived from PMDA embrittled during the thermal imidization process, which may be due to a rigid structure of PMDA. The other films were tough and flexible and could be creased without cracking.

One-pot synthetic method using NMP as a solvent was also carried out for polymerization of the diamine mono-
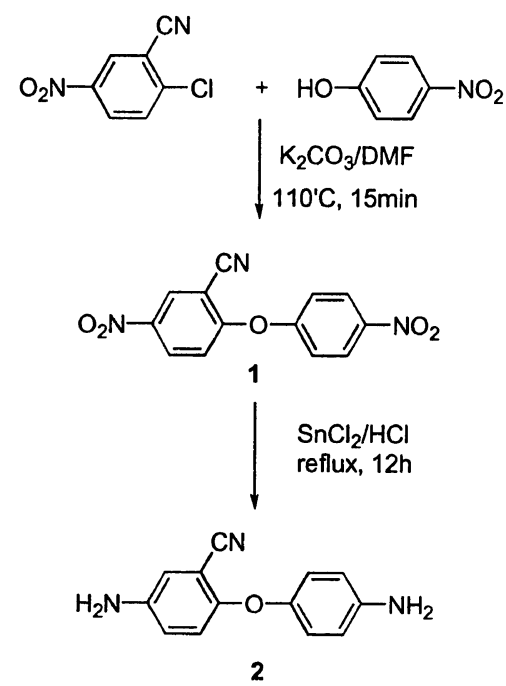

Scheme 1. Synthesis of 2-cyano-4,4'-diaminodiphenyl ether (2).

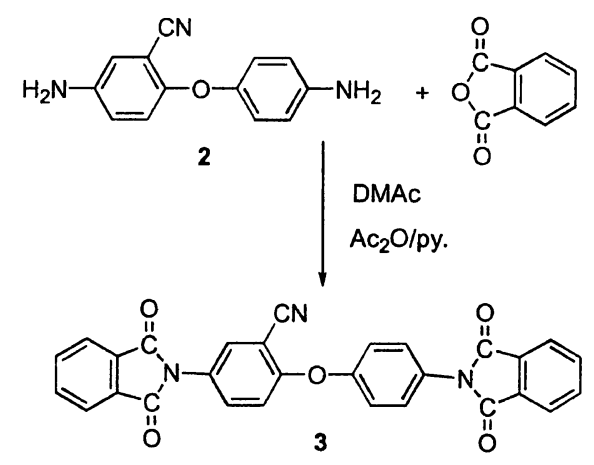

Scheme 2. Model compound of polyimide.
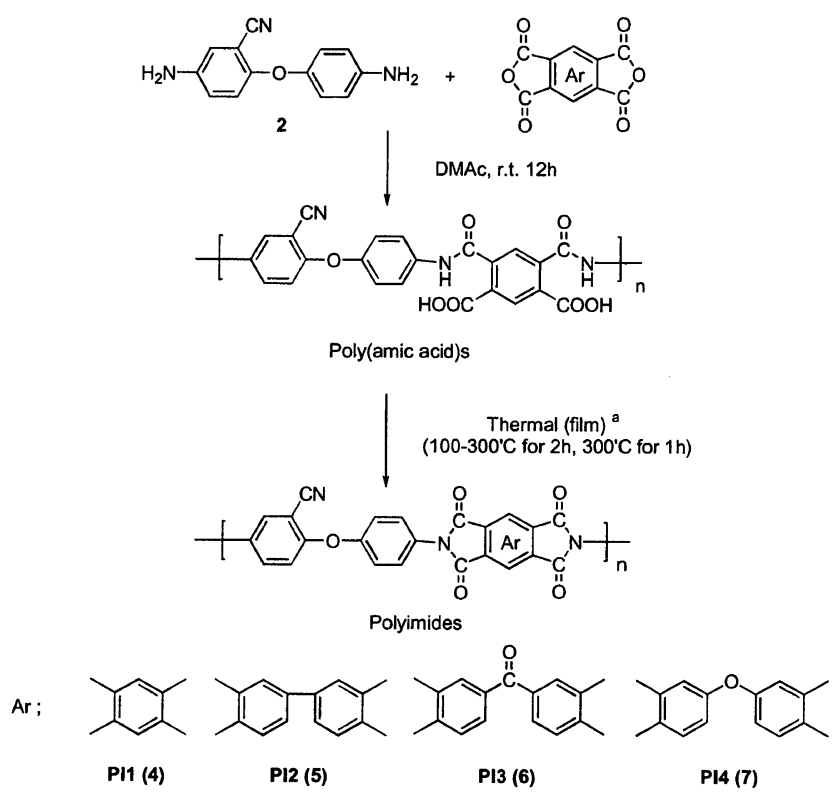

a. For PIl, $100-350^{\circ} \mathrm{C}$ for $3 \mathrm{~h}, 350^{\circ} \mathrm{C}$ for $1 \mathrm{~h}$

Scheme 3. Synthesis of polyimides by thermal imidization.

mer 2 with ODPA and BTDA (Scheme 4). In the case of ODPA, the polyimide PI4' remained soluble in NMP af- 
<smiles>N#Cc1cc(N)ccc1Oc1ccc(N)cc1</smiles><smiles>O=c1oc(=O)c2cc3c(=O)oc(=O)c3cc12</smiles>

NMP ( $20 \%$ solution) r.t., $12 \mathrm{~h}$

NMP addition Chlorobenzene r.t. $\sim 180^{\prime} \mathrm{C}, 3 \mathrm{~h}$ 180 190'C, $9 \mathrm{~h}$

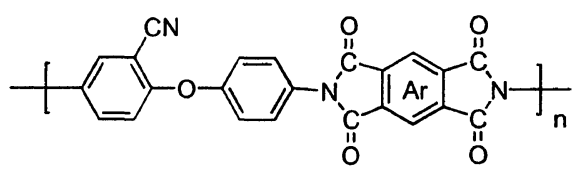

Polyimides

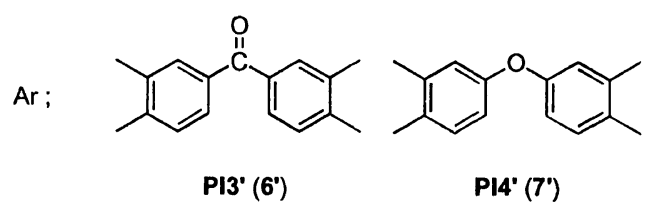

Scheme 4. Synthesis of polyimides by solution imidization.

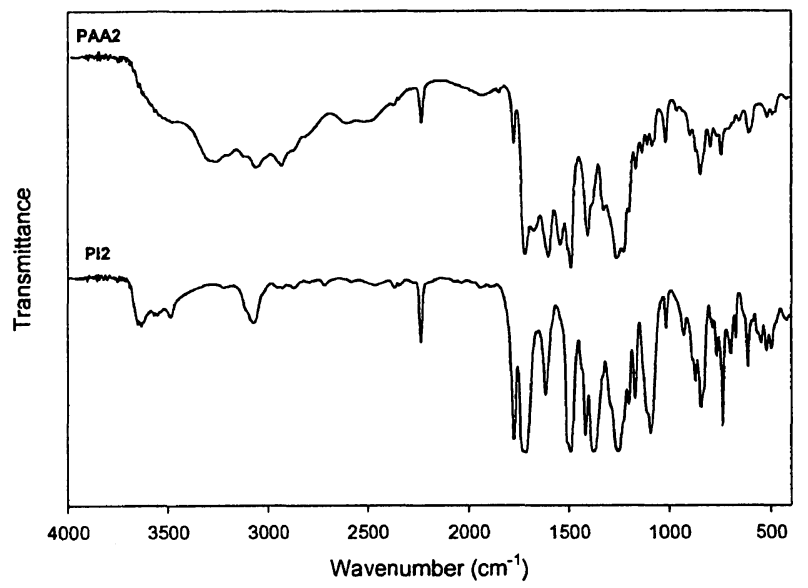

Figure 1. IR Spectra of PAA2 and PI2 (5).

ter imidization, but in the case of polyimide (PI3') from 2 and BTDA, gelation occurred during imidization. However, PI4' was partially soluble only in hot polar aprotic solvent such as DMF and NMP, after precipitation. The polyimides were obtained in quantitative yields and

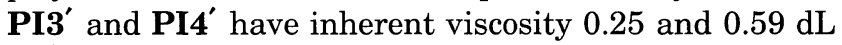
$\mathrm{g}^{-1}$ in $\mathrm{H}_{2} \mathrm{SO}_{4}$, respectively.

The formation of polyimides was confirmed by FT-IR spectroscopy. The F'T-IR spectra of PI2 and poly(amic acid) (PAA2) are shown in Figure 1. FT-IR spectra of the poly(amic acid)s show the absorption bands at 3400$2900 \mathrm{~cm}^{-1}$ corresponding to amide (-NH-) and acid (-OH) stretching, $1718 \mathrm{~cm}^{-1}$ to $\mathrm{C}=\mathrm{O}$ stretching of carboxylic acid, $1655 \mathrm{~cm}^{-1}$ to $\mathrm{C}=\mathrm{O}$ stretching of amide, and $1544 \mathrm{~cm}^{-1}$ to $\mathrm{C}-\mathrm{N}$ stretching of amide. The characteristic absorption bands of the imide ring appear near 1775 $\mathrm{cm}^{-1}$ corresponding to asymmetric $\mathrm{C}=\mathrm{O}$ stretching, $1716 \mathrm{~cm}^{-1}$ to symmetric $\mathrm{C}=\mathrm{O}$ stretching, $1376 \mathrm{~cm}^{-1}$ to C-N stretching, 1092 and $739 \mathrm{~cm}^{-1}$ to imide ring defor-
Table I. Properties of the PIs with cyano groups

\begin{tabular}{|c|c|c|c|c|c|c|c|}
\hline & \multirow{2}{*}{$\frac{\eta_{\text {inh }^{\mathrm{a}}}}{\mathrm{dL} \mathrm{g}^{-1}}$} & \multicolumn{2}{|c|}{$T_{\mathrm{g}} /{ }^{\circ} \mathrm{C}$} & \multicolumn{2}{|c|}{$T_{\mathrm{d}} /{ }^{\circ} \mathrm{C}^{\mathrm{d}}$} & \multirow{2}{*}{$\frac{\text { Char Yield }^{\mathrm{e}}}{\%}$} & \multirow{2}{*}{$\frac{\mathrm{CTE}^{\mathrm{f}}}{\mathrm{ppm}^{\circ} \mathrm{C}^{-1}}$} \\
\hline & & $\mathrm{DSC}^{\mathrm{b}}$ & TMA $^{\mathrm{c}}$ & $\mathrm{N}_{2}$ & Air & & \\
\hline PI1 & 0.47 & - & 308 & 540 & 540 & 61 & 39.5 \\
\hline PI2 & 0.73 & 303 & 305 & 557 & 565 & 66 & 48.3 \\
\hline PI3 & 0.49 & 286 & 285 & 546 & 550 & 62 & 41.6 \\
\hline PI4 & 0.51 & 273 & 271 & 534 & 533 & 57 & 45.0 \\
\hline
\end{tabular}

${ }^{\text {a }}$ Inherent viscosity of poly(amic acid)s in DMAc $\left(0.5 \mathrm{~g} \mathrm{dL}^{-1}\right)$ at $30^{\circ} \mathrm{C} .{ }^{\mathrm{b}} T_{\mathrm{g}}$ was measured by DSC at a heating rate of $10^{\circ} \mathrm{C} \mathrm{min}^{-1}$. ${ }^{c} T_{\mathrm{g}}$ was measured by TMA at a heating rate of $5^{\circ} \mathrm{C} \mathrm{min}^{-1}$. ${ }^{\mathrm{d}}$ Five percent weight loss temperature was measured by TGA at a heating rate of $10^{\circ} \mathrm{C} \mathrm{min}^{-1}$. ${ }^{e}$ Char yield was measured by TGA in $\mathrm{N}_{2}$ with heating rate of $10^{\circ} \mathrm{C} \mathrm{min}{ }^{-1}$. ${ }^{\mathrm{f}}$ Coefficient of thermal expansion was measured by TMA with heating rate of $5^{\circ} \mathrm{C} \min ^{-1}$ at the temperature range from $50^{\circ} \mathrm{C}$ to $250^{\circ} \mathrm{C}$.
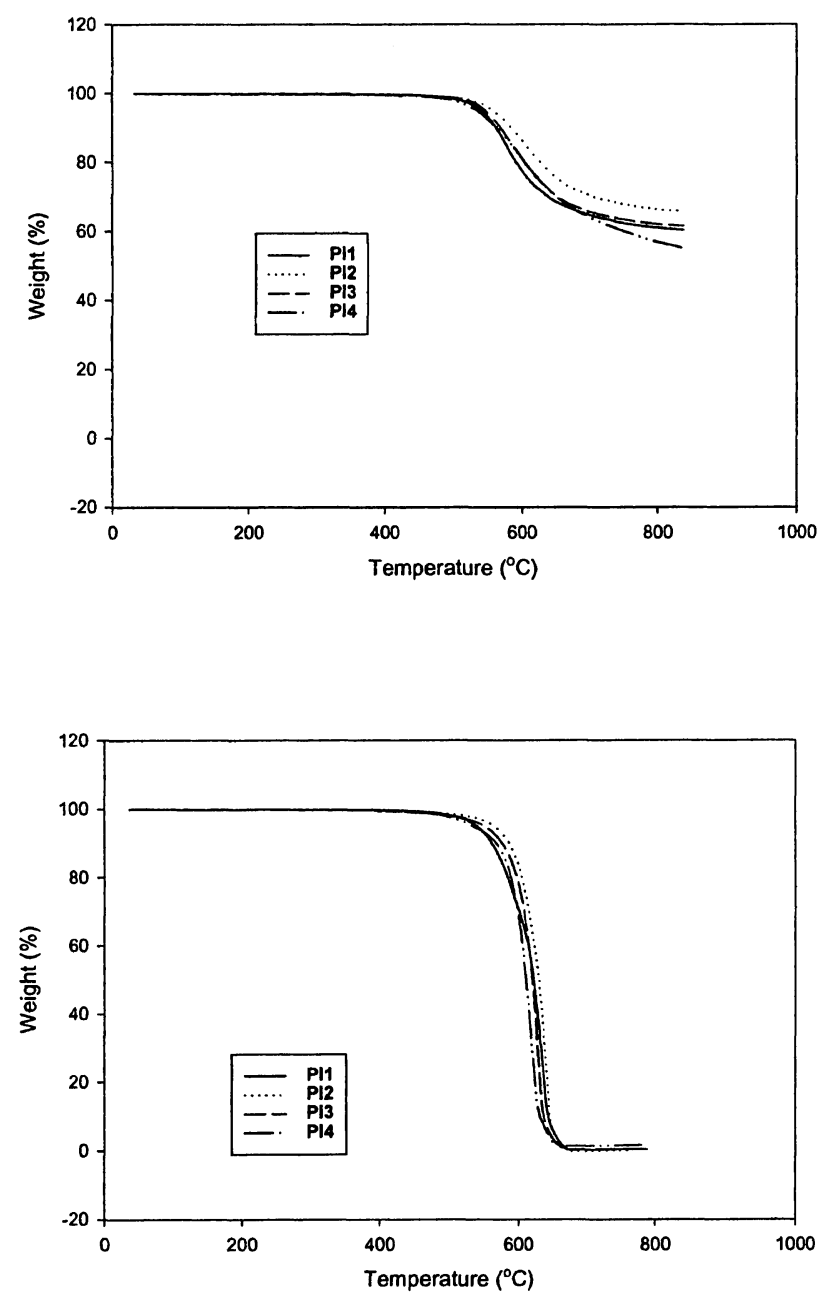

Figure 2. TGA curves of PI1, PI2, PI3, and PI4 in $\mathrm{N}_{2}$ (top) and in air (bottom).

mation. The strong absorption around $2234 \mathrm{~cm}^{-1}$ is assigned to the $\mathrm{C} \equiv \mathrm{N}$ stretching. FT-IR spectra of the synthesized polyimides show same patterns regardless of their imidization method.

Thermal behavior of all the polyimides was evaluated with DSC, TGA, and TMA (Table I). The TGA curves of the polyimides are shown in Figure 2. Five percent weight loss temperatures are in the range of 534 to $557^{\circ} \mathrm{C}$ in nitrogen, and 533 to $565^{\circ} \mathrm{C}$ in air. Generally, aromatic polyimides have the tendency to form charge- 


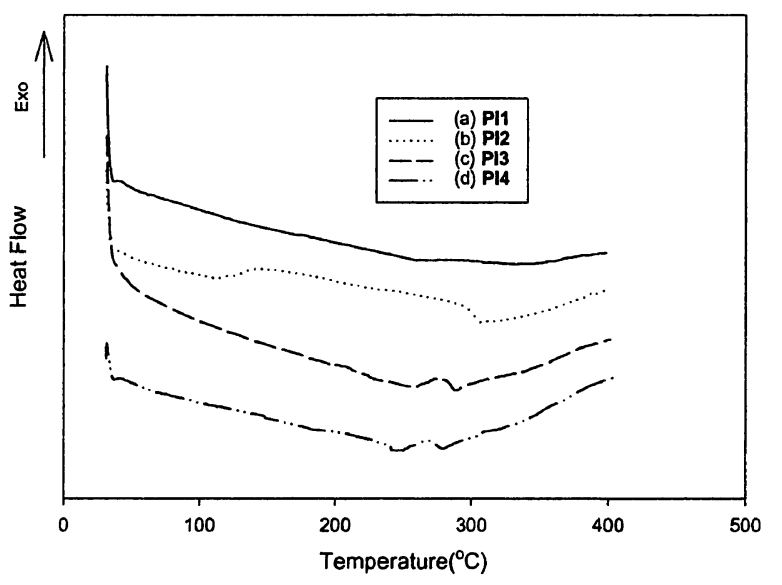

Figure 3. DSC curves of PIs: (a)PI1, (b)PI2, (c)PI3, and (d)PI4.

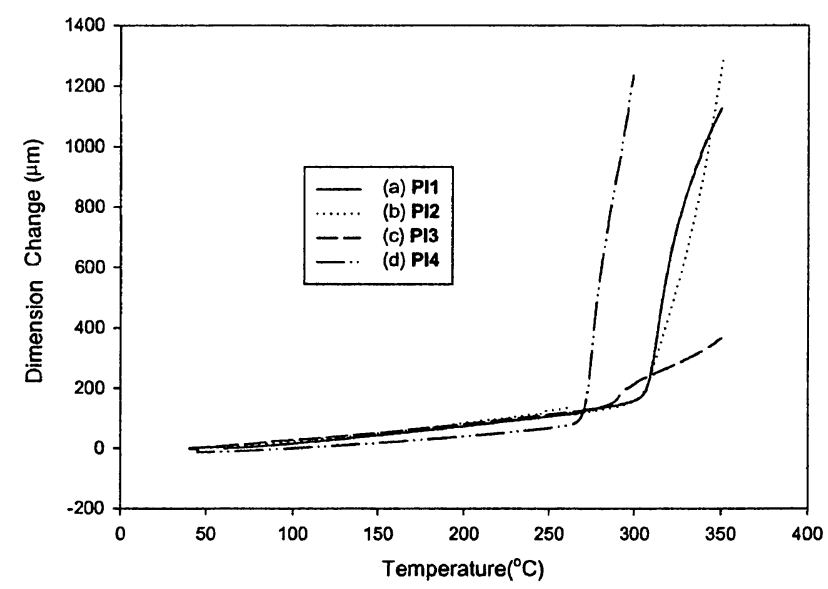

Figure 4. TMA curves of PIs: (a)PI1, (b)PI2, (c)PI3, and (d)PI4

transfer complex and strong interchain packing. The chains interact with each other via a charge-transfer or electronic polarization mechanism. The stability of the cyano functional groups may be caused by intermolecular interaction of polyimides. The cyano functional groups may participate in the interactions of polyimide chains and become less vulnerable to thermooxidative reactions. The amount of carbonized residue (char yield) of polyimides in nitrogen atmosphere was in the range of 57 to $66 \%$ even at $800^{\circ} \mathrm{C}$. The DSC curves are shown in Figure 3 . The glass transition temperatures $\left(T_{\mathrm{g}}\right)$ of theses polyimides were observed in the range of 273 to $303^{\circ} \mathrm{C}$ depending on the structure of dianhydride component and decreased with decreasing rigidity of the polymer backbone. Polyimide PI1 did not exhibit discernible $T_{\mathrm{g}}$ by DSC. The TMA curves are shown in Figure 4 . The coefficients of thermal expansion (CTE) of the polyimides range from 41.6 to $51.9 \mathrm{ppm}{ }^{\circ} \mathrm{C}^{-1}$. CTEs are associated with the rigidity and linearity of the polymer chain, which affect the chain packing. In general, as the size/ bulkiness of the substituents increases, so does the CTE of polyimide films. ${ }^{13}$ The CTE of Kapton ${ }^{\mathrm{TM}}$ (PMDA-ODA) is $21.6 \mathrm{ppm}^{\circ} \mathrm{C}^{-1}$. The CTE and the solubility of PI1 indicate that cyano group may interfere chain-chain interaction of polyimide but the size of the pendent cyano group is not big enough to improve solubility. Thermal properties of the polyimides are comparable to those synthe-

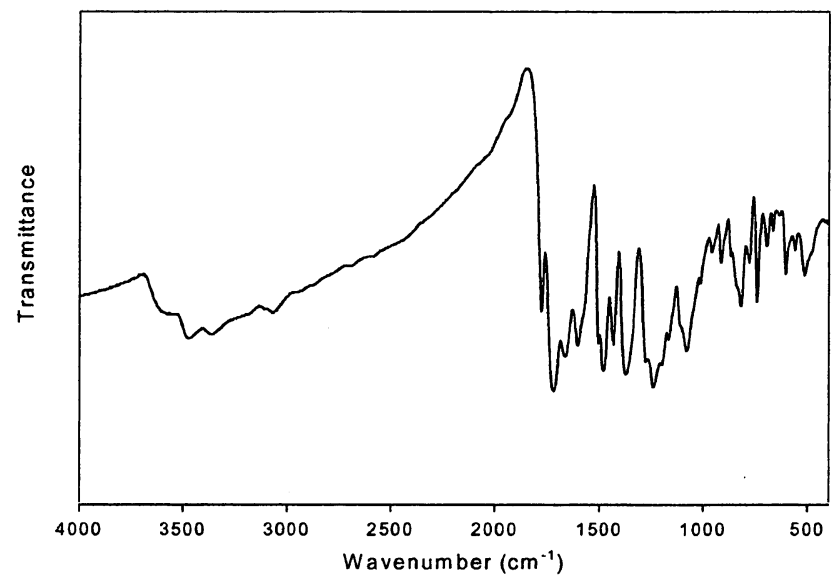

Figure 5. IR Spectrum of PI4' $\left.{ }^{\prime} \mathbf{7}^{\prime}\right)$ after reprecipitated from concentrated $\mathrm{H}_{2} \mathrm{SO}_{4}$.

sized from $4,4^{\prime}$-diaminodiphenyl ether. ${ }^{14}$

Since the polyimides synthesized via one-pot synthetic method, PI $3^{\prime}\left(6^{\prime}\right)$ and PI 4' $\left.\mathbf{( 7}^{\prime}\right)$, were dissolved only in concentrated $\mathrm{H}_{2} \mathrm{SO}_{4}$ at $30^{\circ} \mathrm{C}$, the inherent viscosities were measured in concentrated $\mathrm{H}_{2} \mathrm{SO}_{4}$ and the values are 0.25 and $0.59 \mathrm{dL} \mathrm{g}^{-1}$, respectively. But FT-IR spectra of the polyimides after reprecipitated from concentrated $\mathrm{H}_{2} \mathrm{SO}_{4}$ do not show any $\mathrm{C} \equiv \mathrm{N}$ peak, but show $\mathrm{C}=$ $\mathrm{O}$ stretching peak of carboxylic acid at $1670 \mathrm{~cm}^{-1}$ (Figure 5), indicating that all the cyano groups were hydrolyzed to carboxylic acid. The reprecipitated polymers are dissolved well in polar aprotic solvents without heating, and the inherent viscosity values of the hydrolyzed polyimides measured in DMAc are similar to those measured in $\mathrm{H}_{2} \mathrm{SO}_{4}$.

\section{CONCLUSION}

The polyimides with cyano pendant groups was synthesized from the unsymmetrical diamine, 2-cyano-4,4'diaminodiphenylether, and the dianhydride monomers. The polyimides obtained by thermal or solution imidization method are not soluble in any organic solvents except the polyimide made from ODPA by solution imidization that has limited solubility in polar aprotic solvents. However, the polyimides made from the diamine 2 and ODPA or BTDA become soluble in organic solvents when the cyano groups are hydrolyzed to carboxylic acid. Thermal properties of the polyimides with cyano pendant groups are comparable to those of the polyimides that do not have cyano pendant groups.

\section{REFERENCES}

1. D. Wilson, H. D. Stenzenberger, and P. M. Hergenrother, Ed., "Polyimides", Chapman and Hall, New York, N.Y., 1990.

2. M. K. Ghosh and K. L. Mittal, Ed., "Polyimides: Fundamentals and Applications," Marcel Dekker, Inc., New York, N.Y., 1996.

3. S. J. Hwang and A. E. Hoyt, Trends Polym. Sci., 3, 262 (1995).

4. a) F. W. Harris and S. L. C. Hu, High Perform Polym., 1, 3 (1989). b) S. Z. D. Cheng, F. E. Arnold, A. Zhang, S. L. C. Hu, and F. W. Harris, Macromolecules, 24, 5856 (1991). c) S. Z. D. Cheng, Z. Wu, M. Eashoo, S. L. C. Hu, and F. W. Harris, Polymer, 32, 1803 (1991). d) M. Eashoo, D. Shen, Z. Wu, C. 
J. Lee, F. W. Harris, and S. Z. D. Cheng, Polymer, 34, 3207 (1993).

5. W. R. Shiang and E. P. Woo, J. Polym. Sci., Polym. Chem. Ed., 31, 2081 (1993).

6. T. Matsuudra, Y. Hasuda, S. Nishi, and N. Yamada, Macromolecules, 24, 5001 (1991).

7. M. E. Rogers, H. Grubbs, A. Brennan, D. Rodrigues, G. L. Wilkes, and J. E. McGrath, in "Advances in Polyimide Science and Technology: Proceedings on the 4th International Conference on Polyimides", C. Fefer, M. M. Khojastech, and M. S. Htoo, Ed., Technomic, Lancaster, PA, 1993, p 33.
8. J. L. Hedrick and J. W. Labadie, J. Polym. Sci., Polym. Chem. Ed., 30, 104 (1992).

9. P. M. Hergenrother and S. Havens, Macromolecules, 27, 4659 (1994).

10. J. A. Mikroyannidis, J. Polym. Sci., Part A: Polym. Chem., 35, 1303 (1997).

11. S. Yosida and A. S. Hay, Macromolecules, 30, 5979 (1997).

12. I. S. Chung and S. Y. Kim, Macromolecules, 33, 3190 (2000).

13. T. Swiatoslaw and C. A. Brian, Macromolecules, 27, 1136 (1994).

14. C. E. Sroog, Prog. Polym. Sci., 16, 561 (1991). 